\title{
Revised predictive equations for salt intrusion modelling in estuaries
}

\author{
J. I. A. Gisen ${ }^{1,2}$, H. H. G. Savenije ${ }^{1}$, and R. C. Nijzink ${ }^{1}$ \\ ${ }^{1}$ Water Management, Civil Engineering and Geosciences, Deflt University of Technology, Stevinweg 1, \\ 2628CN Delft, the Netherlands \\ ${ }^{2}$ Civil Engineering and Earth Resources, Universiti Malaysia Pahang, Lebuhraya Tun Razak, \\ 26300 Gambang, Kuantan, Malaysia
}

Correspondence to: J. I. A. Gisen (j.isabellaanakgisen@tudeflt.nl, isabella@ump.edu.my)

Received: 17 December 2014 - Published in Hydrol. Earth Syst. Sci. Discuss.: 16 January 2015

Accepted: 2 June 2015 - Published: 18 June 2015

\begin{abstract}
For one-dimensional salt intrusion models to be predictive, we need predictive equations to link model parameters to observable hydraulic and geometric variables. The one-dimensional model of Savenije (1993b) made use of predictive equations for the Van der Burgh coefficient $K$ and the dispersion at the seaward boundary $D_{0}$. Here we have improved these equations by using an expanded database, including new previously un-surveyed estuaries. Furthermore, we derived a revised predictive equation for the dispersion at tidal average condition and with the boundary situated at the well identifiable inflection point where the estuary changes from wave-dominated to tide-dominated geometry. We used 89 salinity profiles in 30 estuaries (including seven recently studied estuaries in Malaysia), and empirically derived a range of equations using various combinations of dimensionless parameters. We split our data in two separated data sets: (1) with more reliable data for calibration, and (2) with less reliable data for validation. The dimensionless parameters that gave the best performance depended on the geometry, tidal strength, friction and the Richardson number. The limitation of the equations is that the friction is generally unknown. In order to overcome this problem, a coupling has been made with the analytical hydraulic model of Cai et al. (2012), which makes use of observed tidal damping and by which the friction can be determined.
\end{abstract}

\section{Introduction}

Predictive methods to determine salinity profiles in estuaries can be very useful to water resources managers, particularly when applied to ungauged estuaries where only a minimal amount of data are available. Before any decision is made on collecting detailed field observations, it is useful to obtain a first estimate of the strength and range of the salt intrusion in the area of interest. Such estimate can be made if there are predictive equations available to compute the longitudinal salinity profile along the estuary. With reliable predictive equations, water managers are able to estimate how far salt water intrudes into the river system under different circumstances, and more importantly, how interventions may change this situation.

The one-dimensional salt intrusion model of Savenije (1993b) makes use of the Van der Burgh and dispersion equations to represent the longitudinal variation of the salinity. The Van der Burgh and dispersion coefficient at the ocean boundary are obtained by calibration of the simulated salinity curve to observations. Savenije (1993b) established a predictive equation for each of these parameters, so that the longitudinal salinity distribution could be estimated when data were lacking or to monitor the impact of interventions, such as dredging or fresh water withdrawal. The predictive equations have subsequently been modified and tested by several researchers including Savenije (2005), Nguyen and Savenije (2006), Kuijper and van Rijn (2011) and Shaha and Cho (2009).

In this paper, we shall revisit the predictive equations in the light of new insights on how friction and estuary shape affect tidal mixing by deriving a relationship between several governing parameters, making use of the salinity measurements from 30 estuaries including seven new field observations in previously ungauged estuaries in Malaysia that were sampled through a consistent approach. As a result, we present the fully revised and more accurate predictive equations for 
the Van der Burgh coefficient and for the boundary value of the dispersion at a well identifiable location, based on tidal average (TA) condition.

\section{One-dimensional analytical salt intrusion model}

The analytical one-dimensional salinity model developed by Savenije (1993b, 2005, 2012), presented below, is used to simulate the salinity profile in the estuaries studied. In a steady-state situation, the partial temporal derivative in the salt balance equation is zero. Considering a constant fresh water discharge $Q_{\mathrm{f}}\left[\mathrm{L}^{3} \mathrm{~T}^{-1}\right]$ and tidally averaged crosssectional area $A\left[\mathrm{~L}^{3}\right]$, the salt balance equation for tidal average (TA) condition can then be written as

$S-S_{\mathrm{f}}=-\frac{A}{\left|Q_{\mathrm{f}}\right|} D \frac{\mathrm{d} S}{\mathrm{~d} x}$,

where $S=S(x)\left[\mathrm{ML}^{-3}\right]$ and $D=D(x)\left[\mathrm{L}^{2} \mathrm{~T}^{-1}\right]$ are the salinity and dispersion at TA condition. Since discharge has a negative value, the absolute value of $Q_{\mathrm{f}}$ is taken in Eq. (1). $S_{\mathrm{f}}\left[\mathrm{ML}^{-3}\right]$ represents the fresh water salinity. In 1972, Van der Burgh derived an empirical equation for the TA dispersion making use of a large amount of salinity measurements in the Rotterdam Waterway. The equation is then revisited by Savenije $(2005,2012)$ who described the relation between dispersion and salinity to be

$\frac{\mathrm{d} D}{\mathrm{~d} x}=-K \frac{\left|Q_{\mathrm{f}}\right|}{A}$

in which $K^{[-]}$is defined as the Van der Burgh coefficient (shape factor). Substituting Eq. (1) into Eq. (2), the differential equation for the tidally averaged longitudinal salinity distribution is expressed as

$$
\frac{\mathrm{d} S}{S-S_{\mathrm{f}}}=\frac{1}{K} \frac{\mathrm{d} D}{D} \text {. }
$$

Integration of Eq. (3) leads to

$$
\frac{S-S_{\mathrm{f}}}{S_{0}-S_{\mathrm{f}}}=\left(\frac{D}{D_{0}}\right)^{1 / K} \text {. }
$$

The symbols $S\left[\mathrm{ML}^{-3}\right]$ and $D\left[\mathrm{~L}^{2} \mathrm{~T}^{-1}\right]$ are the steady-state salinity and dispersion coefficient at location $x$, while $S_{0}$ $\left[\mathrm{ML}^{-3}\right]$ and $D_{0}\left[\mathrm{~L}^{2} \mathrm{~T}^{-1}\right]$ are the salinity and dispersion at the estuary mouth. In alluvial estuaries, the variation of the estuaries shape over the distance upstream can be expressed in an exponential function (Savenije, 2005, 2012; Nguyen and Savenije, 2006; Zhang et al., 2011) as

$$
\begin{aligned}
& A=A_{0} \exp \left(-\frac{x}{a}\right) \\
& B=B_{0} \exp \left(-\frac{x}{b}\right),
\end{aligned}
$$

where $a[\mathrm{~L}]$ and $b[\mathrm{~L}]$ representing the cross-sectional area and width convergence length, $A_{0}\left[\mathrm{~L}^{2}\right]$ and $B_{0}[\mathrm{~L}]$ are the cross-sectional area and width at the mouth, $B[\mathrm{~L}]$ is the width of estuary at distance $x$ [L] (towards upstream). Substituting the exponential relation of Eq. (5) into Eq. (2) and the integration gives

$$
\begin{aligned}
& \frac{D}{D_{0}}=1-\beta\left[\exp \left(\frac{x}{a}\right)-1\right] \\
& \text { with } \beta=\frac{K a\left|Q_{\mathrm{f}}\right|}{D_{0} A_{0}} .
\end{aligned}
$$

Here, $\beta[-]$ is the dispersion reduction rate. At the salt intrusion limit (upstream) where only fresh water discharge exists, the dispersion coefficient becomes zero and $x$ is equal to the salt intrusion length $L[\mathrm{~L}]$. Hence, the intrusion length is expressed by

$L=a \ln \left(\frac{1}{\beta}+1\right)$.

Equations (4)-(9) are the general equations used to compute the longitudinal salinity distribution.

\section{Existing predictive equations}

\subsection{Van der Burgh's coefficient}

Van der Burgh's coefficient $K$ is also known as the "shape factor" in the salinity curve (Savenije, 1993a). Based on salinity measurements of 15 estuaries, Savenije found that $K$ is strongly related to the geometry (the convergence length $a$ or $b$ and the width $B$ [L]) and its influence is more significant at the tail of the salinity curve (upstream). Moreover, Savenije $(1986,1989)$ observed that every estuary had its own characteristic value of $K$, ranging from zero to one. Assuming that the Van der Burgh coefficient is not time dependent, Savenije (1993b) established an empirical predictive equation for $K$ as

$$
K=0.16 \times 10^{-6} \frac{h_{0}^{0.69} g^{1.12} T^{2.24}}{H_{0}^{0.59} b^{1.10} B_{0}^{0.13}},
$$

where $h_{0}[\mathrm{~L}], H_{0}[\mathrm{~L}]$ and $B_{0}[\mathrm{~L}]$ are the depth, tidal range and width at the estuary mouth, respectively. The symbol $T$ [T] represents the tidal period, while $b[\mathrm{~L}]$ is the width convergence length, and $g\left[\mathrm{~L} \mathrm{~T}^{-2}\right]$ is the gravity acceleration. More than 10 years later, Savenije (2005) and Nguyen and Savenije (2006) made used of an expanded database, modified the predictive equation involving more parameters:

$$
\begin{aligned}
& K=0.3 \times 10^{-3}\left(\frac{E}{H}\right)^{0.65}\left(\frac{E}{C^{2}}\right)^{0.39} \\
& \left(1-\delta_{H} b\right)^{-2.0}\left(\frac{b}{a}\right)^{0.85}\left(\frac{E a}{A^{\prime}}\right)^{0.14} .
\end{aligned}
$$

The symbols $E[\mathrm{~L}], H[\mathrm{~L}]$ and $A^{\prime}\left[\mathrm{L}^{2}\right]$ refer to the tidal excursion, tidal range and a boundary value for the cross-sectional 
area, respectively. This relation had a correlation of 0.93 and seemed very promising. However, as can be seen from the equation, the Chezy roughness $C\left[\mathrm{~L}^{0.5} \mathrm{~T}^{-1}\right]$ and damping $\delta_{H}$ $\left[\mathrm{L}^{-1}\right]$ had to be computed from tidal dynamics analysis.

\subsection{Dispersion coefficient}

Dispersion is not a physical parameter; it is rather the product of averaging, representing the mixing of saline and fresh water in an estuary as a result of residual circulation induced by density gradients (gravitational circulation) and tidal movement. In salt intrusion modelling, the definition of dispersion is often unclear as it is scale dependent and not directly measurable. The role of dispersion is only meaningful if it is related to the appropriate temporal and spatial scale of mixing, which here we identify as the tidal period (timescale), tidal excursion (longitudinal mixing length), estuary width (lateral mixing length) and depth (vertical mixing length). A physically based description of the dispersion would allow the analytical solution of the salt intrusion profile.

Dispersion due to gravitational circulation has been studied since 1957, as summarized by Fischer (1976). This type of dispersion is also known as density-driven dispersion between the two main sources: sea water and fresh river water. Schultz and Simmons (1957) were some of the first to relate buoyancy to mixing in estuaries, whereby they introduced the ratio between fresh water discharge and tidal volume to represent the degree of stratification. This ratio is also known as the Canter-Cremers number $N_{[-]}$as defined by Harleman and Abraham (1966). The buoyancy effect or stratification in an estuary can also be represented by the estuarine Richardson number $N_{\mathrm{r}}[-]$ which is the ratio of potential energy of the buoyant fresh water to the kinetic energy of the tide:

$N_{\mathrm{r}}=\frac{\Delta \rho}{\rho} \frac{g h}{v^{2}} \frac{Q_{\mathrm{f}} T}{A E}$,

where $\rho\left[\mathrm{ML}^{-3}\right]$ is the water density, $\Delta \rho\left[\mathrm{ML}^{-3}\right]$ is the density difference over the salt intrusion length, and $v\left[\mathrm{~L} \mathrm{~T}^{-1}\right]$ is the tidal velocity amplitude. The difference between $N$ and $N_{\mathrm{r}}$ lies in the densimetric Froude number $F_{\mathrm{d}}[-]$ which is expressed as

$F_{\mathrm{d}}=\frac{\rho}{\Delta \rho} \cdot \frac{v^{2}}{g h}$.

Since then, researchers have tried to look for a relation between dispersion and estuarine numbers. Laboratory results of WES flume (Van Rees and Rigter, 1969; Rigter, 1973), Delft flume (Ippen and Harleman, 1961, 1967) and Daniels (1974) indicated an agreement with the result of Fischer (1972) in computing the salt intrusion length, using shear velocity instead of mean velocity in the estuarine Richardson number. Subsequently, the relationship between the dispersion and modified $N_{\mathrm{r}}$ also gave good correlation for all the other cases (mostly flume experiments). Thatcher and Harle- man (1972) suggested that the longitudinal dispersion is proportional to the salinity gradient and included this in his one dimensional analytical salt intrusion model, which later was used by Fischer (1972) to model the vertical salinity and velocity distribution. A disadvantage of all these methods was that they did not account for convergence (implicitly assuming an infinitely large convergence length) and that the tidal excursion, as the most important mixing length scale, was missing in the derivations.

Deriving the dimensionless dispersion coefficient from scaling the steady-state salt balance equation, Savenije (2005) developed the following empirical predictive relation for the longitudinal dispersion at the estuary mouth for high water slack (HWS):

$D_{0}^{\mathrm{HWS}}=1400 \frac{\bar{h}}{a} N_{\mathrm{r}}^{0.5}(v E)$.

The estuary shape was represented by the ratio of the averaged depth $\bar{h}[\mathrm{~L}]$ to the convergence length $a$, while the dispersion was made dimensionless by the tidal velocity amplitude and tidal excursion which was not considered in any of the earlier studies. The applicability of these predictive equations has been widely tested in many estuaries including multi-channel estuaries.

Kuijper and van Rijn (2011) later modified the empirical equation using salinity measurements from 13 estuaries, in which they introduced the inclusion of the dimensionless friction $\left(C^{2} / g\right)$. The predictive equation was divided into two depending on the types of channel - prismatic and convergent:

convergent channel:

$D_{0}=60 \alpha_{c} \sqrt{\pi}\left(\frac{\sqrt{\Delta \rho g h_{0} / \rho}}{v}\right)\left(\frac{C^{2}}{g}\right)\left(\frac{|u|}{v}\right)^{0.5} \frac{E}{a} v h_{0}$,

prismatic channel:

$D_{0}=6 \alpha_{c} \sqrt{\pi}\left(\frac{\sqrt{\Delta \rho g h_{0} / \rho}}{v}\right)\left(\frac{C^{2}}{g}\right)\left(\frac{|u|}{v}\right)^{0.5} v h_{0}$,

where $u\left[\mathrm{~L} \mathrm{~T}^{-1}\right]$ is the fresh water velocity. These equations can be used to calculate dispersion locally at any location. The coefficient $\alpha_{c}$ is an additional calibration coefficient with the range of 0.7 to 1.3. From the result of Kuijper and van Rijn (2011), it is observed that the $\alpha_{c}$ coefficients for prismatic channels have values that are closer to 1.0 , whereas for convergent channels, the coefficients are scattered within the range.

\subsection{Salt intrusion length}

Several researchers have tried to develop a general relation for the salt intrusion length. The development of such predictive equations was done empirically based on a reasonable amount of data. A pioneer effort was made by van der 
Burgh (1972), making use of prototype information from the Dutch and German estuaries. His equation for the salt intrusion length as summarized by Savenije (1992, 1993b, 2005) is as follows:

$L^{\mathrm{TA}}=26 \pi \frac{h_{0}}{K} F^{-1.0} N^{-0.5}$

with $F=\frac{v}{\sqrt{g h_{0}}}$

and $\quad N=\frac{\left|Q_{\mathrm{f}}\right| T}{P_{\mathrm{t}}}=\frac{A|u| T}{A v T} \cdot \pi=\frac{|u|}{v} \cdot \pi$.

In this equation, $L^{\mathrm{TA}}[\mathrm{L}]$ is the salt intrusion length at TA situation, $F[-]$ is the Froude number, and $P_{\mathrm{t}}\left[\mathrm{L}^{3}\right]$ is the tidal flood volume. Fischer (1974) re-analysed the data by Rigter (1973) and included the Darcy-Weisbach roughness and the densimetric Froude number, resulting in

$L^{\mathrm{LWS}}=17.7 \frac{h_{0}}{f_{\mathrm{D}}^{0.625}} F_{\mathrm{d}}^{-0.75} N^{-0.25}$,

where LWS denotes low water slack. It is important to note here that Van der Burgh's coefficient $K$ is replaced by the Darcy-Weisbach roughness $f_{\mathrm{D}}=8 g / C^{2}[-]$ and $F$ is represented by the densimetric Froude number $F_{\mathrm{d}}[-]$.

About 20 years later, Van Os and Abraham (1990) established a similar equation with a slightly different coefficient:

$L^{\mathrm{LWS}}=4.4 \frac{h_{0}}{f_{\mathrm{D}}}\left(F_{\mathrm{d}}^{-1} N^{-1}\right)$.

All these methods were based on flume data with prismatic geometry. Savenije $(1993 b, 2005,2012)$ who explicitly accounted for channel convergence and the tidal excursion, developed a predictive equation for the salt intrusion length at HWS. The reasoning was that the maximum salt intrusion length occurs during HWS, which is most important for water resources management. Based on Eq. (14), the equation reads as

$L^{\mathrm{HWS}}=a \ln \left(1400 \frac{\bar{h} E_{0} v_{0}}{K a^{2} u_{0}} N_{\mathrm{r}}^{0.5}+1\right)$,

where $v_{0}\left[\mathrm{~L} \mathrm{~T}^{-1}\right]$ is the tidal velocity amplitude at the mouth. It is worth noting that Savenije follows Van der Burgh's equation, with an additional shape indicator referring to the area convergence length $a$.

Most of the empirical equations discussed above are based on LWS except for Van der Burgh's and Savenije's methods which are based on TA and HWS, respectively. However, they can easily be brought in agreement with each other by adding $E / 2$ or $E$ to $L^{\mathrm{HWS}}$, respectively. Here, we aim to develop a universal predictive equation for estimating the Van der Burgh and dispersion coefficient for TA condition, which can be applied in the salt intrusion model to predict the salinity profile for any estuary worldwide under different tidal and flood conditions.

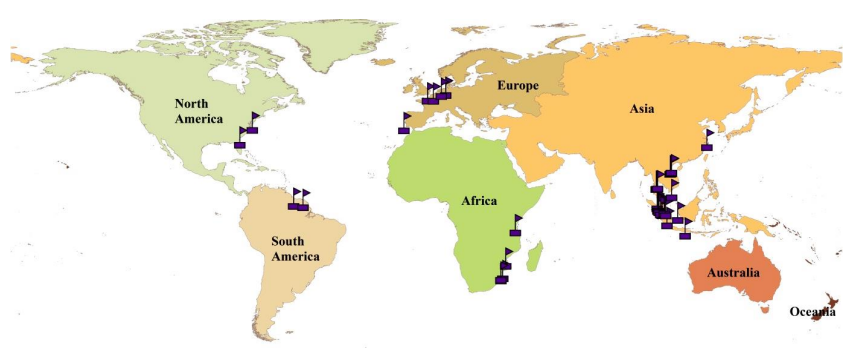

Figure 1. Global map showing the locations of the estuaries studied.

\section{Methods}

In this paper, the main focus is on the mixing mechanisms which lead to longitudinal dispersion in estuaries: the tideand density-driven dispersion. Key parameters are developed based on measurable parameters of geometry, tidal hydraulics and fresh water discharge. In total 89 measurements data of 30 estuaries worldwide have been used to develop the predictive equations. Measurements in seven newly surveyed estuaries were collected from 2011 to 2013 in Malaysia (Gisen et al., 2015), whereas the remainder were compiled by revisiting existing data available in the database of Savenije (2005) and from professional reports. The locations of the estuaries studied are displayed in Fig. 1.

Adjustments have been made to the geometry (see Fig. S1 in the Supplement) and salinity analysis for some of the estuaries to ensure consistency in the input data used. The entire data set was split into two: reliable and less reliable data. The reliable data set have been used to develop the predictive equations, whereas the less reliable ones have been used for verification purposes. The study was performed based on Savenije's (1993b, 2005, 2012) method for predicting $K$ and $D_{0}$ with some modifications. The modifications include:

- All geometry and tide information used refers to the well identifiable inflection point $x_{1}$ as the boundary condition.

- Analyses were performed on TA condition instead of HWS, which is consistent with the geometry information.

- Estuary roughness and the ratio of estuary width to river width have been added in the predictive equations.

- The parameters chosen are mostly independent and easy to observe without the need for prior calibration.

Although the predictive equations are based on the TA situation, one can still compute the salinity distribution for both LWS and HWS by shifting the curve over $E / 2$ in seaward and landward direction. 


\subsection{Selecting the dimensionless ratios}

Revising the parameters selected by Savenije (1993b, 2005), we found that the latter contained some parameters that required tidal dynamics analysis while one of the ratios was not dimensionless. The following are the dimensionless ratios selected for the revised predictive equation for the Van der Burgh coefficient:

$K=f\left(\frac{B_{\mathrm{f}}}{B_{1}}, \frac{g}{C^{2}}, \frac{E_{1}}{H_{1}}, \frac{\bar{h}_{1}}{b_{2}}, \frac{\bar{h}_{1}}{H_{1}}, \frac{\lambda_{1}}{E_{1}}\right)$,

where $B_{\mathrm{f}}[\mathrm{L}]$ is the river regime width (located upstream of the tidal limit where the convergence of the river width is modest and near constant), and $\lambda_{1}=T \sqrt{g \bar{h}_{1} / r_{\mathrm{S}}}$ [L] is the wave length at the inflection point with $r_{\mathrm{s}}$ [-] being the storage width ratio (defined as the ratio between storage width and stream width). The symbols $B_{1}[\mathrm{~L}], E_{1}[\mathrm{~L}], h_{1}[\mathrm{~L}], H_{1}$ [L] and $b_{2}[\mathrm{~L}]$ represent the estuary width, tidal excursion, averaged estuary depth, tidal range and width convergence length at the inflection point $x_{1}$. It is worth noting that the roughness $C=K_{\mathrm{m}} \bar{h}_{1}^{1 / 6}$ was obtained through calibration using the tidal dynamics solution of Cai et al. (2012) which makes use of observed tidal damping. In the above equation, it can be seen that all parameters used have been defined at the inflection point $x_{1}$. It is also important to note that the convergence length adopted is of the second reach and not of the first part of the estuary. Generally the tidal indicators $E$ and $H$ are defined at the mouth. In order to obtain the tidal excursion and tidal damping at the inflection point, a projection can be made considering tidal damping as follows (Kuijper and van Rijn, 2011):

$H_{1}=H_{0} \cdot \exp \left(\delta_{H} x_{1}\right)$

$E_{1}=E_{0} \cdot \exp \left(\delta_{H} x_{1}\right)$,

where the damping factor $\delta_{H}$ also follows from the tidal dynamics simulation of Cai et al. (2012). The values of $H_{1}$ and $E_{1}$ used in the dimensionless ratios represent the condition of spring tide, where $v$ is considered to be close to $1 \mathrm{~m} \mathrm{~s}^{-1}$ (Bruun and Gerritsen, 1960; Pethick, 1984; Langbein, 1963). This is to ensure that $K$ is time independent representing a general characteristic of an estuary. As a result, $E$ essentially reflects the tidal period as described in (see also Table 1)

$E=\frac{v T}{\pi}$

For the dispersion coefficient, eight dimensionless ratios have been selected with 18 different types of equations including the one of Savenije (1993b, 2005) as benchmark. The dispersion coefficient is represented in dimensionless form as

$$
\begin{aligned}
& \frac{D_{1}}{v_{1} E_{1}}=f\left(N_{\mathrm{r} 1}, \frac{h_{1}}{a_{2}}, \frac{g}{C^{2}}, \frac{H_{1}}{E_{1}}, \frac{h_{1}}{E_{1}}, \frac{\lambda_{1}}{E_{1}}, \frac{\lambda_{1}}{a_{2}}, \frac{B_{1}}{h_{1}}\right) \\
& \text { with: } \quad N_{\mathrm{r} 1}=\frac{\Delta \rho}{\rho} \frac{g h_{1}}{v_{1}^{2}} \frac{Q_{\mathrm{f}} T}{A_{1} E_{1}},
\end{aligned}
$$

where $N_{\mathrm{r} 1}[-]$ is the estuarine Richardson number with $v_{1}$ $\left[\mathrm{L} \mathrm{T}^{-1}\right]$ being the tidal velocity amplitude, both at the inflection point. It is important to note that the values taken for $E_{1}$ and $H_{1}$ in the dispersion analysis are based on the real-time data captured during measurements and the depth is referring to the depth at the inflection point. In general, the density difference between the saline and fresh water is taken as $(25 / 35) S_{0} \mathrm{~kg} \mathrm{~m}^{-3}$ and the fresh water density as $1000 \mathrm{~kg} \mathrm{~m}^{-3}$. The fresh water discharge data were adjusted for the seven newly surveyed estuaries so that the runoff contribution downstream of the gauging station was also considered in the analysis. Stepwise multiple regression analysis has been used to identify the best combination of the dimensionless ratios in predicting $K$ and $D_{1}$. The efficiency of the established equations was examined by comparing the correlation coefficient $R^{2}$ and the standard error SE. The predicted results calculated by the most suitable equations were plotted against the calibrated values to evaluate their predictive performance (see Fig. S2 in the Supplement).

\subsection{Substitution of predictive equations in the salt intrusion model}

Since the predictive dispersion is computed at the inflection point $x_{1}$, reverse calculation has to be done to obtain the dispersion at the mouth. This is necessary to enable the simulation of the longitudinal salinity distribution starting from the mouth to the salt intrusion limit. Inverse integration from $x_{1}$ to $x=0$ of Eq. (2) yields for the dispersion at the estuary mouth:

$D_{0}^{\mathrm{TA}}=D_{1}^{\mathrm{TA}}\left\{1+\beta_{\mathrm{rev}}^{\mathrm{TA}}\left[1-\exp \left(-\frac{x_{1}}{a_{1}}\right)\right]\right\}$

with $\quad \beta_{\mathrm{rev}}^{\mathrm{TA}}=\frac{K a_{1}}{\alpha_{1}^{\mathrm{TA}} A_{1}}$

and $\quad \alpha_{1}^{\mathrm{TA}}=\frac{D_{1}^{\mathrm{TA}}}{\left|Q_{\mathrm{f}}\right|}$

where $\beta_{\text {rev }}[-]$ is the reversed dispersion reduction rate, whereas $A_{1}\left[\mathrm{~L}^{2}\right], D_{1}\left[\mathrm{~L}^{2} \mathrm{~T}^{-1}\right]$ and $\alpha_{1}\left[\mathrm{~L}^{-1}\right]$ are the crosssectional area, dispersion coefficient and mixing number at the inflection point, respectively. It is important to note that the convergence length $a_{1}[\mathrm{~L}]$ applied in Eqs. (29) and (30) is of the first section of the estuary. The relation between dispersion and salinity is then expressed by 
Table 1. Data used to develop the predictive equation for the Van der Burgh coefficient $K$.

\begin{tabular}{|c|c|c|c|c|c|c|c|c|c|c|c|c|c|c|c|}
\hline No & Estuary & $\begin{array}{r}A_{1} \\
{\left[10^{3}\right]} \\
\left(\mathrm{m}^{2}\right)\end{array}$ & $\begin{array}{r}a_{2} \\
(\mathrm{~km})\end{array}$ & $\begin{array}{r}B_{1} \\
(\mathrm{~m})\end{array}$ & $\begin{array}{r}B_{\mathrm{f}} \\
(\mathrm{m})\end{array}$ & $\begin{array}{r}b_{2} \\
(\mathrm{~km})\end{array}$ & $\begin{array}{r}\bar{h}_{1} \\
(\mathrm{~m})\end{array}$ & $\begin{array}{r}x_{1} \\
(\mathrm{~km})\end{array}$ & $\begin{array}{l}H_{0} \\
(\mathrm{~m})\end{array}$ & $\begin{array}{c}E_{0} \\
(\mathrm{~km})\end{array}$ & $\begin{array}{c}T \\
\text { (h) }\end{array}$ & $K_{\mathrm{m}}$ & $\begin{array}{r}\delta_{\mathrm{H}} \\
\left(10^{-6} \mathrm{~m}^{-1}\right)\end{array}$ & $\begin{array}{c}K \\
\mathrm{Cal}\end{array}$ & $\begin{array}{c}K \\
\text { Pre }\end{array}$ \\
\hline \multicolumn{16}{|c|}{ Reliable sets for calibration } \\
\hline 1 & Kurau & 0.7 & 46 & 130 & 20 & 28 & 6.2 & 3.6 & 2.3 & 14 & 12 & 30 & -6.30 & 0.40 & 0.35 \\
\hline 2 & Perak & 9.2 & 37 & 2070 & 130 & 21 & 6.3 & 4.0 & 2.8 & 14 & 12 & 65 & 3.00 & 0.20 & 0.24 \\
\hline 3 & Bernam & 4.5 & 25 & 1270 & 45 & 17 & 5.3 & 4.3 & 2.9 & 14 & 12 & 70 & 1.70 & 0.20 & 0.22 \\
\hline 4 & Selangor & 1.0 & 13 & 270 & 35 & 13 & 3.7 & 2.8 & 4.0 & 14 & 12 & 40 & -3.70 & 0.34 & 0.42 \\
\hline 5 & Muar & 1.6 & 100 & 280 & 55 & 31 & 8.2 & 3.9 & 2.0 & 14 & 12 & 45 & -2.68 & 0.25 & 0.32 \\
\hline 6 & Endau & 2.0 & 44 & 310 & 72 & 44 & 6.5 & 4.8 & 1.9 & 14 & 12 & 45 & -1.30 & 0.40 & 0.33 \\
\hline 7 & Maputo & 4.7 & 16 & 1150 & 100 & 16 & 4.1 & 5.1 & 3.3 & 14 & 12 & 58 & 2.00 & 0.38 & 0.32 \\
\hline 8 & Thames & 10.9 & 23 & 780 & 50 & 40 & 8.2 & 31.0 & 5.3 & 14 & 12 & 45 & 1.10 & 0.20 & 0.24 \\
\hline 9 & Corantijn & 26.8 & 64 & 5000 & 400 & 48 & 6.7 & 18.0 & 3.1 & 14 & 12 & 40 & -1.70 & 0.21 & 0.27 \\
\hline 10 & Sinnamary & 1.1 & 39 & 470 & 95 & 12 & 3.9 & 2.7 & 3.3 & 14 & 12 & 40 & -5.00 & 0.45 & 0.46 \\
\hline 11 & MaeKlong & 1.1 & 150 & 240 & 150 & 150 & 4.6 & 3.2 & 3.6 & 14 & 12 & 40 & -4.20 & 0.30 & 0.48 \\
\hline 12 & Lalang & 2.9 & 167 & 360 & 130 & 94 & 10.3 & 0.0 & 2.6 & 28 & 24 & 84 & -0.54 & 0.65 & 0.57 \\
\hline 13 & Limpopo & 1.1 & 115 & 180 & 90 & 115 & 6.3 & 20.0 & 1.9 & 14 & 12 & 43 & 1.70 & 0.50 & 0.38 \\
\hline 14 & Tha Chin & 1.4 & 87 & 260 & 45 & 87 & 5.6 & 5.0 & 2.6 & 14 & 12 & 50 & -5.50 & 0.35 & 0.31 \\
\hline 15 & ChaoPhya & 3.1 & 130 & 470 & 200 & 130 & 6.5 & 12.0 & 3.4 & 28 & 24 & 65 & -2.20 & 0.75 & 0.71 \\
\hline 16 & Edisto & 5.2 & 15 & 1250 & 60 & 15 & 4.1 & 2.0 & 3.2 & 14 & 12 & 30 & -8.80 & 0.35 & 0.31 \\
\hline 17 & Elbe_Flanders & 27.3 & 70 & 3040 & 350 & 80 & 8.5 & 33.0 & 4.7 & 14 & 12 & 32 & 2.00 & 0.30 & 0.27 \\
\hline $17 \mathrm{a}$ & Elbe_Kuijper & 46.0 & 66 & 4500 & 350 & 66 & 10.2 & 0.0 & 4.7 & 14 & 12 & 32 & 2.00 & 0.30 & 0.25 \\
\hline $17 b$ & Elbe_Savenije & 43.0 & 66 & 2880 & 350 & 50 & 11.7 & 0.0 & 4.6 & 14 & 12 & 32 & 2.00 & 0.30 & 0.28 \\
\hline 18 & Pangani & 0.9 & 15 & 270 & 35 & 15 & 3.2 & 3.1 & 4.2 & 14 & 12 & 42 & 10.00 & 0.60 & 0.41 \\
\hline 19 & Linggi & 1.5 & 8 & 320 & 25 & 13 & 3.2 & 0.5 & 2.0 & 14 & 12 & 30 & -14.00 & 0.30 & 0.36 \\
\hline 20 & Landak & 2.0 & 60 & 230 & 100 & 60 & 8.7 & 0.0 & 1.6 & 28 & 24 & 45 & -6.70 & 0.60 & 0.69 \\
\hline \multicolumn{16}{|c|}{ Less reliable sets for verification } \\
\hline $21^{3,4}$ & Delaware & 255.0 & 41 & 37655 & 120 & 42 & 6.4 & 0.0 & 1.8 & 14 & 12 & 55 & 0.65 & 0.22 & 0.09 \\
\hline $22^{2,3}$ & Westerschelde & 150.0 & 27 & 16000 & 50 & 27 & 9.4 & 0.0 & 4.0 & 14 & 12 & 46 & 2.80 & 0.25 & 0.10 \\
\hline $23^{1,2,4}$ & Pungue & 14.5 & 19 & 5200 & 50 & 19 & 2.8 & 0.0 & 6.7 & 14 & 12 & 31 & -8.50 & 0.30 & 0.22 \\
\hline $24^{2}$ & Incomati & 1.1 & 40 & 380 & 22 & 40 & 2.8 & 15.0 & 3.3 & 14 & 12 & 56 & -19.90 & 0.15 & 0.34 \\
\hline $25^{2,4}$ & Solo & 2.1 & 226 & 225 & 95 & 226 & 9.2 & 0.0 & 1.8 & 28 & 24 & 31 & 3.00 & 0.60 & 0.64 \\
\hline $26^{2,4}$ & Eems & 120.0 & 19 & 31623 & 55 & 19 & 3.8 & 0.0 & 3.6 & 14 & 12 & 31 & -0.70 & 0.30 & 0.11 \\
\hline $27^{2,3}$ & Tejo & 100.0 & 13 & 20000 & 180 & 13 & 5.0 & 0.0 & 3.6 & 14 & 12 & 56 & 2.20 & 0.90 & 0.16 \\
\hline $28^{2,4}$ & Rompin & 0.8 & 110 & 140 & 50 & 110 & 6.1 & 19.0 & 2.5 & 14 & 12 & 15 & -33.40 & 0.30 & 0.64 \\
\hline $29^{2,4}$ & Ulu Sedili Besar & 0.7 & 38 & 140 & 35 & 49 & 4.1 & 4.3 & 2.5 & 14 & 12 & 30 & -25.50 & 0.30 & 0.45 \\
\hline $30^{1,3}$ & Gambia & 35.7 & 96 & 3700 & 110 & 100 & 8.8 & 33.0 & 1.83 & 14 & 12 & 35 & -1.00 & 0.60 & 0.16 \\
\hline
\end{tabular}

Note: ${ }^{1}$ Non-steady state (NSS); ${ }^{2}$ uncertain discharge (UQ); ${ }^{3}$ non-alluvial (NA); ${ }^{4}$ information lacking (IL).

$$
\begin{array}{ll}
\frac{S^{\mathrm{TA}}-S_{\mathrm{f}}^{\mathrm{TA}}}{S_{0}^{\mathrm{TA}}-S_{\mathrm{f}}^{\mathrm{TA}}}=\left(\frac{D^{\mathrm{TA}}}{D_{0}^{\mathrm{TA}}}\right)^{\frac{1}{K}} & 0 \leq x \leq x_{1} \\
\frac{S^{\mathrm{TA}}-S_{\mathrm{f}}^{\mathrm{TA}}}{S_{1}^{\mathrm{TA}}-S_{\mathrm{f}}^{\mathrm{TA}}}=\left(\frac{D^{\mathrm{TA}}}{D_{1}^{\mathrm{TA}}}\right)^{\frac{1}{K}} & x>x_{1},
\end{array}
$$

where $S_{0}\left[\mathrm{ML}^{-3}\right]$ and $S_{1}\left[\mathrm{ML}^{-3}\right]$ refer to the salinity at the estuary mouth and the inflection point, respectively.

Substituting the tidally average dispersion coefficient into the general form of the salt intrusion length of Savenije (1993b, 2005) yields

$L^{\mathrm{TA}}=x_{1}+a_{2} \ln \left(\frac{1}{\beta_{1}^{\mathrm{TA}}}+1\right)$

with $\beta_{1}^{\mathrm{TA}}=\frac{K a_{2}}{\alpha_{1}^{\mathrm{TA}} A_{1}}$.

Note that all parameters used in these equations refer to the inflection point. We obtain the salinity profile at HWS and LWS by moving the salinity curve over $E / 2$ in the upstream and downstream direction. Similarly, the maximum salt intrusion length can be obtained by shifting the intrusion length at TA in the landward direction by half of the tidal excursion at the mouth as

$$
L^{\mathrm{HWS}}=L^{\mathrm{TA}}+\frac{E_{0}}{2}
$$


and the LWS intrusion length by moving the tidal excursion seaward:

$$
L^{\mathrm{LWS}}=L^{\mathrm{TA}}-\frac{E_{0}}{2} .
$$

\section{Data}

Data were divided into two categories: reliable and less reliable. There are 47 measurements grouped under the reliable data set, and 38 measurements under the less reliable data set (see Table S2 and S3 in the Supplement). This distinction was made based on the following criteria.

Criteria for classifying estuaries as reliable:

- the estuary is generally in steady-state condition;

- the fresh water discharge is estimated, observed or measured correctly;

- the estuary is alluvial and undisturbed;

- complete measurement data for tidal dynamics and salinity analysis are available.

Criteria for classifying estuaries as less reliable:

- The estuary is not in steady state particularly during low river discharge. This depends on the ratio of the timescale of system response to the timescale of discharge reduction (see Savenije, 2012) (NSS).

- The estimation of the fresh water discharge is uncertain (UQ).

- The estuary may not be alluvial (e.g. dredged, modified or constricted by rocky banks) (NA).

- Information on tidal dynamics and salinity is lacking or unclear (IL).

The estuaries that fall under category NSS, UQ, NA and IL are listed in Table 1. It is worth noting that only the reliable set is used in regression analysis. The less reliable ones are merely plotted for verification purpose.

\section{Results and analysis}

\subsection{Predictive equation for the Van der Burgh coefficient $K$}

Results from the stepwise multiple regression analyses show that the best combinations of the dimensionless ratios to rep-

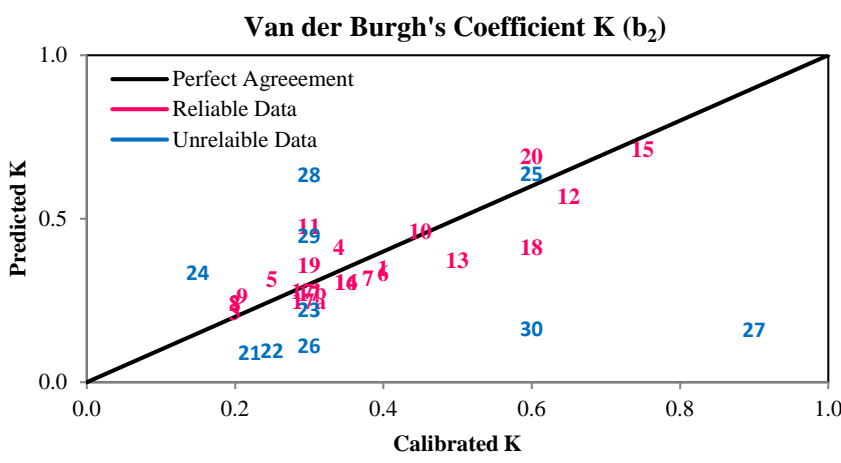

Figure 2. Performance of the predictive equation for the Van der Burgh coefficient against the calibrated values.

resent the Van der Burgh predictive equation are

$$
\begin{aligned}
& K=8.03 \times 10^{-6}\left(\frac{B_{\mathrm{f}}}{B_{1}}\right)^{0.30}\left(\frac{g}{C^{2}}\right)^{0.09}\left(\frac{E_{1}}{H_{1}}\right)^{0.97} \\
& \left(\frac{\bar{h}_{1}}{b_{2}}\right)^{0.11}\left(\frac{H_{1}}{\bar{h}_{1}}\right)^{1.10}\left(\frac{\lambda_{1}}{E_{1}}\right)^{1.68}
\end{aligned}
$$

or

$$
K=151.35 \times 10^{-6}\left(\frac{B_{\mathrm{f}}^{0.30} H_{1}^{0.13} T^{0.97}}{B_{1}^{0.30} C^{0.18} v_{1}^{0.71} b_{2}^{0.11} \bar{h}_{1}^{0.15} r_{\mathrm{s}}^{0.84}}\right),
$$

where Eq. (39) is the simplified form. The correlation coefficient $R^{2}$ and the standard error SE obtained for predictive $K$ equation is 0.72 and 0.11 , respectively. If we had used the cross-sectional area convergence $a_{2}$ instead of $b_{2}$, then the correlation would be slightly poorer. Hence the width convergence is a better indicator, which is fortunate because it is easier to determine. From the equation, we can see that the parameters that have the most influence on the Van der Burgh coefficient is the tidal period, storage width ratio and tidal velocity amplitude which have the power of $0.93,0.84$ and 0.71 , respectively. The importance of the friction appears to be minor, which is also fortunate as $C$ is not directly observable. The estuary to river width ratio shows higher power than the convergence length, which indicates that the width is a better shape indicator. Result from the regression is shown in Table S4 (supplementary material). Finally, we should realize that $0 \leq K \leq 1$ according to Savenije (1993a). For prismatic channels where $b_{2}$ becomes infinity, $K$ approaches zero, implying constant dispersion.

Figure 2 shows the plot of the predicted $K$ against the calibrated value. All the reliable data points appear to fall close to the perfect agreement line. About half the unreliable data points were outliers particularly the Gambia (30) and Tejo (27) estuaries which lie much further away from the perfect agreement line. This is not strange in the sense that the Tejo Estuary is not entirely alluvial, and its narrow and deep mouth caused by a rock outcrop formation turns it into a fjord 
type estuary. As for the Gambia, it is an unsteady-state estuary. Nevertheless, for the rest of the outliers we believe that they would fit better if good data had been available. The results are summarized in Table 1.

\subsection{Predictive equation for the dispersion coefficient $D$}

In this study, 18 combinations of the dimensionless ratios were established by a multiple regression method of which the results are displayed in Table S1 (equations) and Fig. S2 in the Supplement (correlations and standard error). By observing the exponent, it can be seen that the power of the estuarine Richardson number $N_{\mathrm{r}}$ varies little, indicating the clear correlation with $N_{\mathrm{r}}$ compared to the other parameters. The next parameter that has a high exponent is the dimensionless roughness, of which the inclusion improves the correlation. As for the rest of the dimensionless ratios, it appears that the contribution is minimal. Hence, the best equations chosen for further analysis are

$$
\begin{aligned}
\frac{D_{1}^{\mathrm{TA}}}{v_{1} E_{1}} & =0.1167 N_{\mathrm{r}}^{0.57} \\
\frac{D_{1}^{\mathrm{TA}}}{v_{1} E_{1}} & =0.3958 N_{\mathrm{r}}^{0.57}\left(\frac{g}{C^{2}}\right)^{0.21} \\
\frac{D_{1}^{\mathrm{TA}}}{v_{1} E_{1}} & =1.9474\left(N_{\mathrm{r}} \cdot \frac{g}{C^{2}}\right)^{0.51} .
\end{aligned}
$$

More information about the equations tested is provided in the Supplement (Table S1). Equations (40), (41) and (42) correspond with Eqs. (R2), (R4) and (R9) in Table S1.

It is interesting to note that the performance of the benchmark equation of Savenije (1993b, 2005) (Eq. R1) is rather poor, with $R^{2}$ and SE of 0.67 and 0.33 . These significant differences may be caused by the homogenization of the input information (e.g. geometry), and the use of selective data for calibration. With more or less equal performance, it is decided that the simplest equation with the best performance is the most attractive one. Therefore, we conclude that Eq. (41) is the best to predict the tidal average dispersion coefficient at $x_{1}$. This is also theoretically the most attractive, since laboratory experiments of the WES flume (Van Rees and Rigter, 1969; Rigter, 1973), Delft flume (Ippen and Harleman, 1961, 1967) and Daniels (1974) have demonstrated that both $N_{\mathrm{r}}$ and the roughness are key parameters. Nevertheless, if the Chezy roughness is unknown, then Eq. (40) can be applied. Equations (40), (41) and (42) have an $R^{2}$ of $0.84,0.86$ and 0.80 with SE of $0.14,0.13$ and 0.15 , respectively. We can also conclude that although estuary shape is the key in defining $K$, the dispersion boundary condition $D_{1}$ appears to be determined by hydraulic parameters. The detailed results obtained from the regressions are shown in Table S5 (Supplement).

Figure 3 displays the plots of the predicted $D_{1}$ and $\alpha_{1}$ against the calibrated values for both the reliable and less reliable data sets using Eqs. (40), (41) and (42). Here, it is shown that all the reliable data points fall nicely within the range of a factor 1.5. Some of the less reliable data points are also within or near the range except for several obvious outliers such as the Delaware, Schelde, Pungue and Tejo. This is because the Pungue is often in an unsteady-state condition, while the Schelde is dredged, and the Tejo and Delaware are not completely alluvial. In addition, the doubt on the accuracy of the discharge data is also one of the factors contributing to poor results. It can be seen that all the predictive equations selected have underestimated the values of the dispersion coefficient for the outlying data points, indicating a possible underestimation of the river discharge.

Comparing the outliers in both plots, it appears that the unreliable data are distributed closer to the reference lines if the dispersion is represented in term of the mixing number. This implies that the fresh water discharge is partly to blame for the discrepancy. The data used for the regression and results of the predicted dispersion are tabulated in Table S2 in the Supplement.

\subsection{Modified predictive equation for maximum salt intrusion length $L^{\mathrm{HWS}}$}

Comparison between the predicted and calibrated salt intrusion length has been done for HWS condition instead of TA. This is because the salt intrudes furthest into the river system at HWS, and the maximum intrusion is the information water managers are most interested in. Substituting the predictive dispersion Eqs. (40), (41) and (42) into the general form for salt intrusion length yields

$$
\begin{aligned}
& L^{\mathrm{HWS}}=x_{1}+a_{2} \ln \left(0.1167 \frac{E_{1} v_{1}}{K a_{2} u_{1}} N_{\mathrm{r}}^{0.57}+1\right)+\frac{E_{0}}{2} \\
& L^{\mathrm{HWS}}=x_{1}+a_{2} \ln \left(0.3958 \frac{E_{1} v_{1} g^{0.21}}{K a_{2} u_{1} C^{0.42}} N_{\mathrm{r}}^{0.57}+1\right)+\frac{E_{0}}{2} \\
& L^{\mathrm{HWS}}=x_{1}+a_{2} \ln \left(1.9474 \frac{E_{1} v_{1} g^{0.51}}{K a_{2} u_{1} C^{1.02}} N_{\mathrm{r}}^{0.51}+1\right)+\frac{E_{0}}{2},
\end{aligned}
$$

where $u_{1}$ represents the driver flow velocity at the inflection point. Figure 4 shows the performance of these equations in predicting the maximum salt intrusion length. In the plots using Eqs. (43), (44), and (45), all data points fall within the range of factor 1.5 except the Solo Estuary. The list of data and the results are summarized in Table S3 in the Supplement. It appears that the predictive equations overestimated the intrusion length in the Solo Estuary. This may be due to the nearly prismatic shape of the channel which has a very long convergence length of $226 \mathrm{~km}$.

\subsection{Longitudinal salinity profiles}

The salinity curve can be computed by applying Eqs. (32) and (33) with the different dispersion calculated by each of the predictive measures developed. Considering the substantial amount of salinity measurements available, only the 

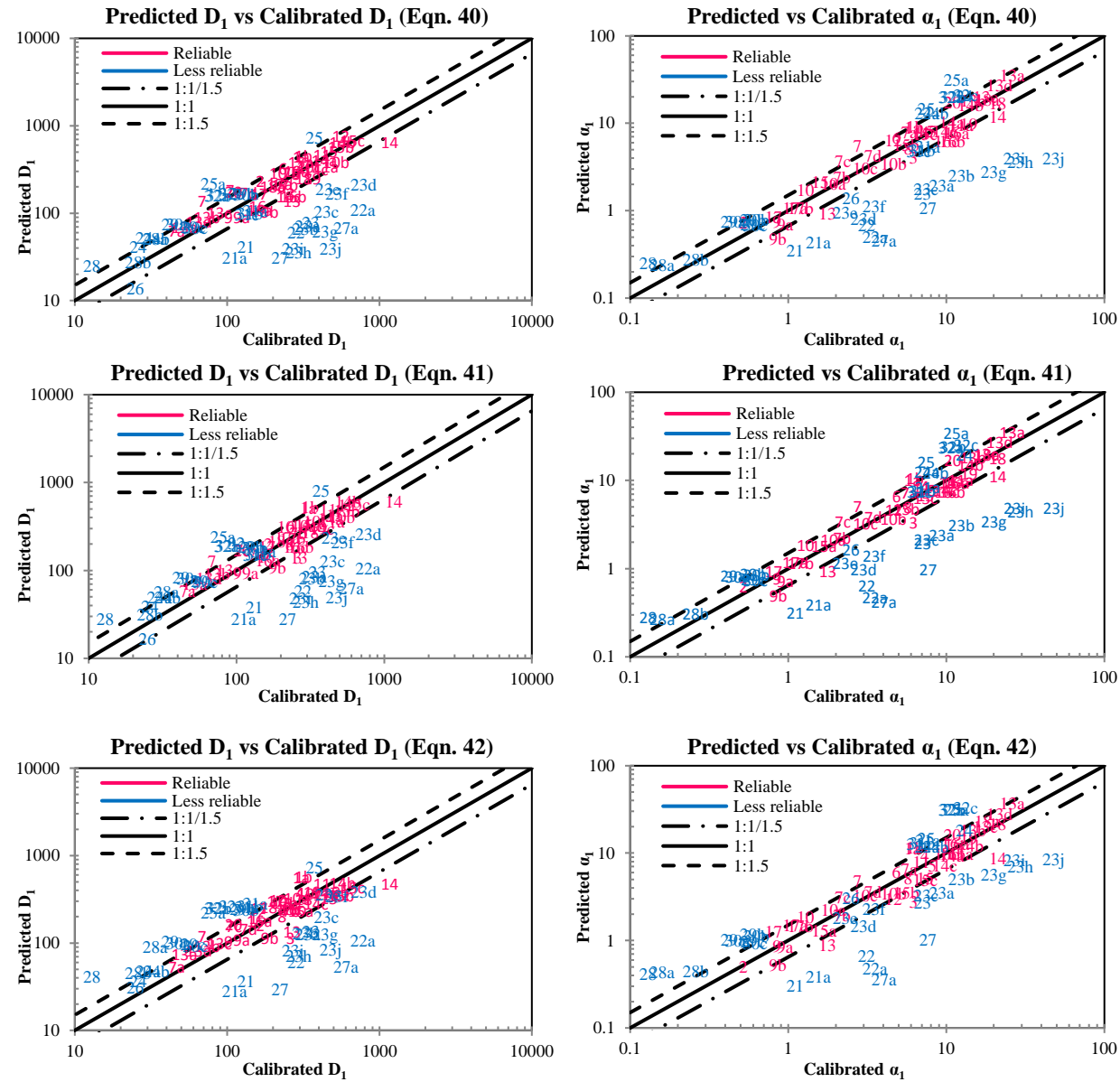

Figure 3. Performance of the predictive equations for the dispersion coefficient (left panel) and mixing number (right panel) against calibrated values.
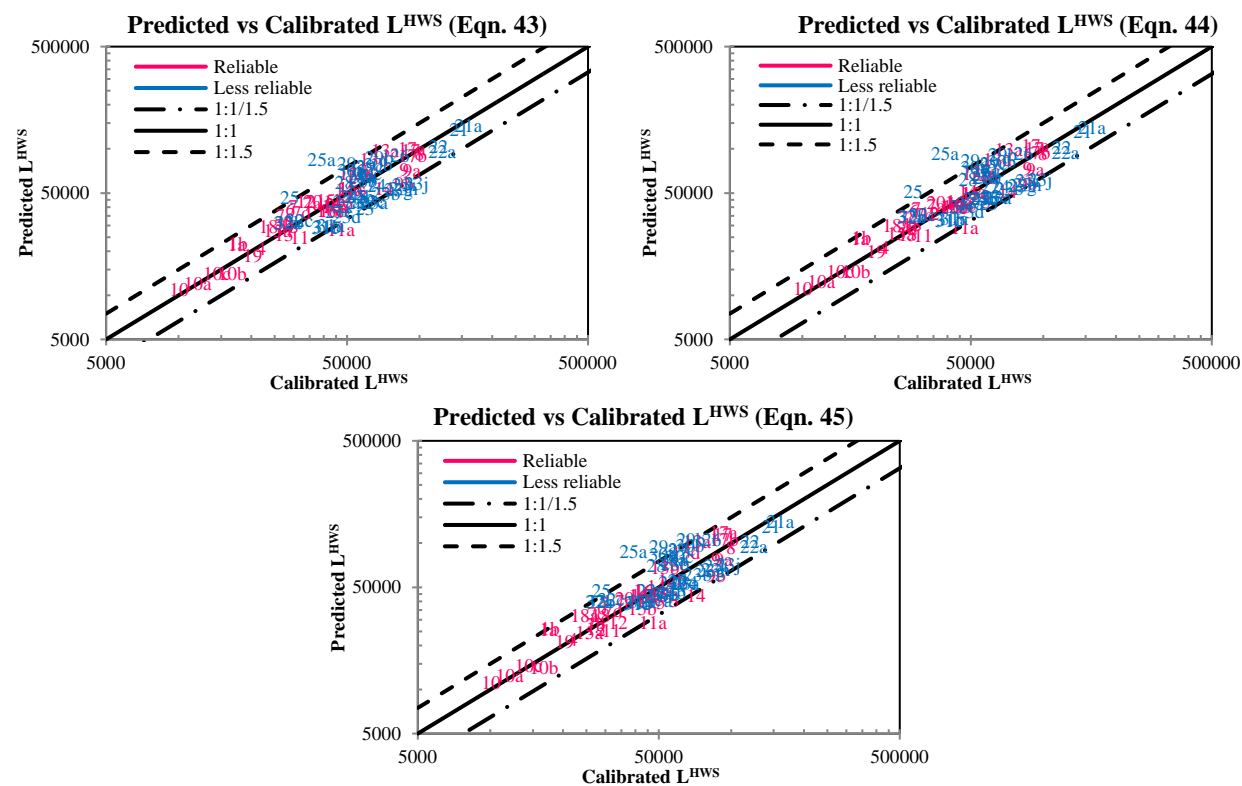

Figure 4. Comparison between predicted and calibrated maximum salt intrusion $L^{\text {HWS }}$ for Eqs. (43), (44) and (45). 

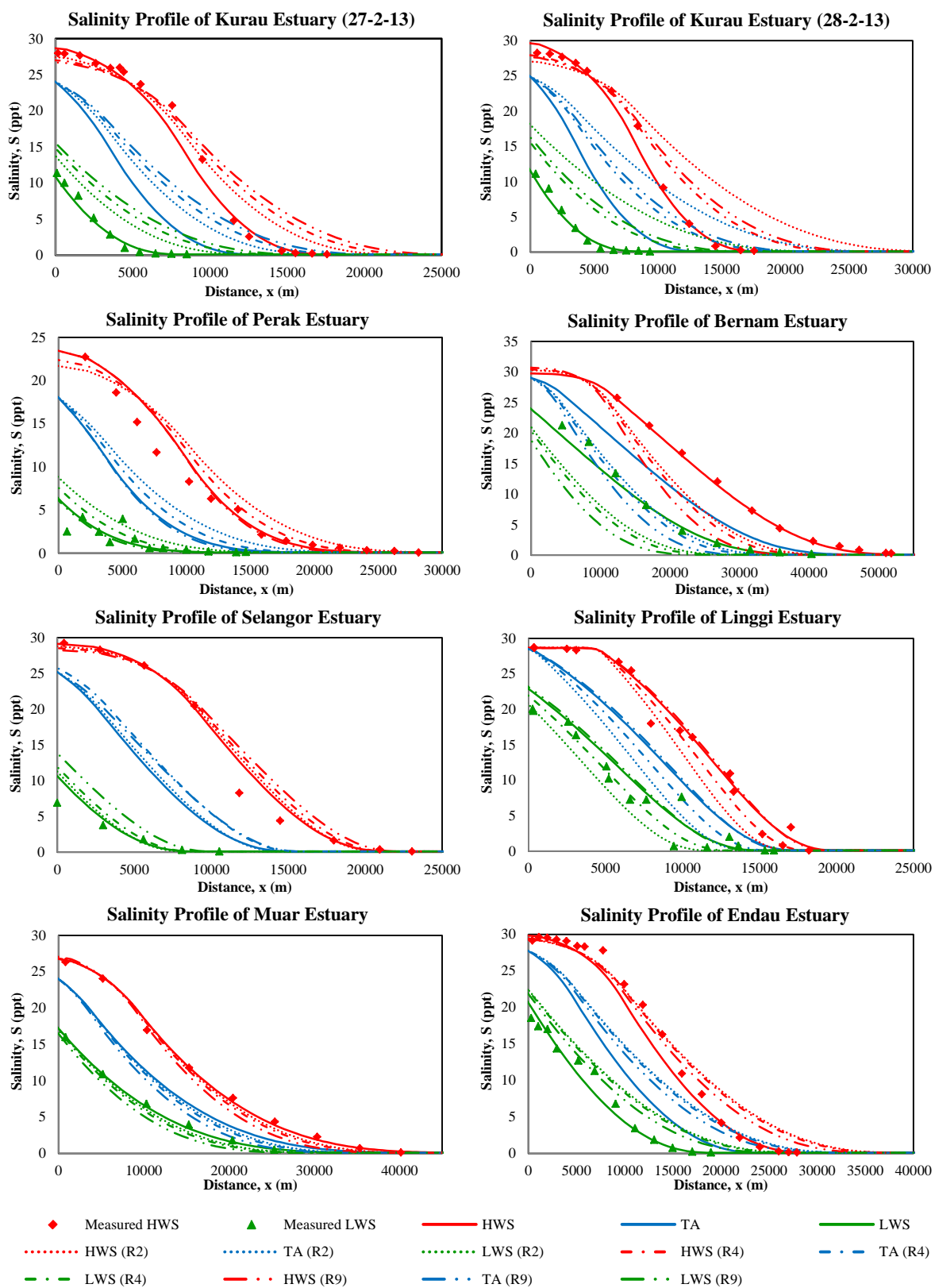

Figure 5. Calibrated (solid lines) and predicted (dashed lines) salinity curves compared to observations (symbols) for HWS, TA and LWS in the seven newly surveyed Malaysian estuaries.

salinity profiles of the seven newly surveyed estuaries are discussed. Plots of all salinity profiles are available as electronic material at the website http://salinityandtides.com. Figure 5 demonstrates the performance of the simulated longitudinal salinity distribution calibrated against the measurement data, and the salinity profile obtained from the predictive equations of $K$ and $D_{1}$.

From the salinity curve comparison, it appears that all the predictive equations did not perform very well for Kurau and Bernam estuaries. This may be caused by the uncertainty in discharge data. The Kurau and Bernam discharge calcula- tions were based on the discharge observed in a small part of the catchments of about 12 and $20 \%$ of the total area, respectively (Gisen and Savenije, 2015). Thus, it is possible that we may have underestimated the discharge draining into the $\mathrm{Ku}-$ rau Estuary, and overestimated the one for Bernam Estuary. It is also interesting to note that Eq. (42) works better in predicting the salinity distribution for some of the estuaries such as the Perak, Linggi and Endau. As for most of the cases, Eq. (41) appears to give the best fit. The difference in the performance of these equations suggests that there is a possibility that the equations are subject to improvement if more 
reliable measurements are available. Thus, it is appropriate to retain the three Eqs. (40), (41), and (42) for consideration.

\section{Discussion}

Before Savenije's (1993a) effort to develop predictive equations for the Van der Burgh and dispersion coefficient, these parameters could only be obtained by calibration. Without site measurements, it was impossible to make any estimate of the salinity distribution along an estuary. The predictive equations of Savenije (1993a, 2005) were able to estimate the value of $K$ and $D$ reasonably well in reference to the calibration data. However, after re-evaluating and re-analysing the available data, we found that the equations do not work as well for all estuaries.

In this study, we have collected an additional 32 salinity profiles from 16 new estuaries for consideration in the analysis. Moreover, the measurements were split into two data sets to make sure that only the reliable data were used for establishing the revised equations. In previous work, the data were not split. The selection process is important so that the results are not influenced by incomplete or uncertain data. Re-examining the available measurements from the old database ensures that all data used are accessible and consistent. The new compilation also provides a section containing important information about each measurement (see electronic additional material - salinity worksheet at http://salintyandtides.com).

Another important modification in this work is the change in the selected boundary condition. In this research, we decided to process the cross-sectional data in reference to the TA situation, whereas previous methods were based on HWS and LWS, which led to inconsistencies because the geometry during low and high water can be different from TA situation. Moreover, in this study we fixed the location of the downstream boundary at the inflection point $x_{1}$ and not at the estuary mouth (adopted by all earlier researchers). The reasons and advantages of moving the downstream boundary to the inflection point are:

- to eliminate the difficulty of determining the exact location of the estuary mouth;

- to reduce the effect from wind and waves;

- to eliminate the dilemma of which geometry parameters to use in the predictive equation.

In Savenije's (1993a, 2005) and Kuijper and van Rijn's (2011) predictive model, the cross-sectional area convergence length applied to calculate the salt intrusion length was the weighted value obtained from an iteration process. With the change of the downstream boundary to $x_{1}$, this process is no longer needed and the predictive measures are more consistent.
The new set of dimensionless ratios proposed in this study to establish the predictive equation for $K$ contains mostly measurable independent parameters. The selection was made based on the existing equations, considering only the parameters that are easy to obtain. The ratio $\left(1-\delta_{H} b\right)$ has been removed from the equation because the tidal damping changes from spring to neap tide. Furthermore, the tidal level tends to increase or decrease when it moves upstream and the changes are highly influenced by fresh water discharge. The river to estuary width ratio has been added in the new equation as an additional geometry indicator besides the depth and convergence length. This ratio appeared to have great influence on $K$.

For the predictive dispersion equation, the ratio of the depth to the convergence length is no longer important, but the longitudinal length scale $E$ and velocity amplitude $v$ remain important in the scaling of $D_{1}$. The elimination of $\bar{h} / a$ allows the new equation to be applied also in prismatic channels. In the old equation, when $a_{2}$ approaching infinity, the calculation became invalid. Since Kuijper and van Rijn (2011) suggested that the friction parameter is related to the vertical mixing, $g / C^{2}$ has been included in this new equation and it indeed improved the correlation. Savenije (2005) did not consider roughness in his predictive equation for dispersion.

Although some improvements and simplicity have been introduced in this study, there are limitations in using the new equations. Until now, we have only taken into account single-network estuaries. Furthermore, it has implicitly been assumed that no water is entering or leaving the tributaries in the estuary region. If there are large tributaries or large areas draining on the estuary, then these should be accounted for. From the plot of Van der Burg's coefficient, we found that the performance in predicting $K$ is rather low. This indicates that the equation has to be used with caution. Another constraint in using the developed equations is the friction factor. The Chezy roughness is not directly measurable and can only be obtained by calibration using a tidal dynamics model. However, if this information is impossible to get, it can be neglected (the correlation only decreases to 0.70 for the predictive equation without roughness). If cross-sectional area information is lacking, then $b_{1}$ can be used to replace $a_{1}$. For the depth estimates, one can make use of the method presented by Gisen and Savenije (2015) which links $\bar{h}_{1}$ to the bankfull discharge.

\section{Conclusions}

Calibrating $K$ and $D_{1}$ is only possible if measurement of the salinity distribution is available. In a situation where data are limited, a predictive equation is required to estimate the desired variables. A good predictive equation should be simple (parameters can be easily measured) and efficient. The predictive equations established in this study consist of mostly 
measurable independent parameters. Options are suggested for the case in which data are very limited. The adjustment of the downstream boundary to the inflection point has clarified the selection of the right geometry parameters to be used and the position of the downstream boundary.

The analysis based on tidal average conditions enables the entire process to be carried out consistently, whereby model and data errors can be reduced. The obtained salt intrusion can easily be converted from TA to HWS by adding half of the tidal excursion. The performance of the predictive equation for $K$ is rather weak with a $R^{2}$ value of 0.72 but still acceptable. For the dispersion, the correlation of 0.86 seems very promising. All the reliable data points fall within a factor of 1.5 for both the predicted $K$ and $D_{1}$ results. Some less reliable ones are also within this range. This indicates that the predictive equations developed are appropriate to be applied in getting a first estimate of $K$ and $D_{1}$. Subsequently, the longitudinal salinity distribution in an estuary can be estimated.

Hence, these tools can be very helpful for water managers and engineering to make preliminary estimates on the salt intrusion in an estuary of interest and to analyse the impact of interventions. Finally, it is recommended to collect more reliable measurements to strengthen the development of the empirical relationships. New data are also required for validation purposes.

\section{The Supplement related to this article is available online at doi:10.5194/hess-19-2791-2015-supplement.}

Acknowledgements. We would like to express our gratitude to: Universiti Teknologi Malaysia (UTM) and colleagues Huayang Cai for their invaluable support and assistance in completing the field works in Malaysia; the Department of Irrigation and Drainage (DID) Malaysia for providing the hydrological data; and Kees Kuijper (Deltares) for sharing the surveyed data of the Elbe Estuary.

Edited by: A. D. Reeves

\section{References}

Bruun, P. and Gerritsen, F.: Stability of Coastal Inlets, North Holland Pub. Co., Amsterdam, 128 pp., 1960.

Cai, H., Savenije, H. H. G., and Toffolon, M.: A new analytical framework for assessing the effect of sea-level rise and dredging on tidal damping in estuaries, J. Geophys. Res.-Oceans, 117, C09023, doi:10.1029/2012JC008000, 2012.

Daniels, D. G.: A Laboratory Study of Estuarine Salinity Intrusion in a Rectangular Channel of Large Aspect Ratio, Hydraul. Eng. Lab. Rep. WHM-17, Univ. Calif., Berkeley, 65 pp., 1974.

Fischer, H. B.: Mass transport mechanisms in partially stratified estuaries, J. Fluid Mech., 53, 671-687, 1972.
Fischer, H. B.: Discussion of "Minimum Length of Salt Intrusion in Estuaries" by Ben P. Rigter, J. Hydr. Eng. Div.-ASCE, 100, 708-713, 1974.

Fischer, H. B.: Mixing and dispersion in estuaries, Ann. Rev. Fluid Mech., 8, 107-133, 1976.

Gisen, J. I. A. and Savenije, H. H. G.: Estimating bankfull discharge and depth in ungauged estuaries, Water Resour. Res., 51, 22982316, 2015.

Gisen, J. I. A., Savenije, H. H. G., Nijzink, R. C., and Abd. Wahab, A. K.: Testing a 1-D analytical salt intrusion model and its predictive equations in Malaysian stuaries, Hydrol. Sci. J., 60, 156-172, 2015.

Harleman, D. R. F. and Abraham, G.: One-Dimensional Analysis of Salinity Intrusion in the Rotterdam Waterway, Hydraulics Laboratory Publ. No. 44, Waterloopkundig Laboratorium, Delft, 1966.

Ippen, A. T. and Harleman, D. R. F.: One-dimensional analysis of salinity intrusion in estuaries, US Army Corps Eng., Waterways Experiment Station, Vicksburg, Miss. Tech. Bull. No. 5, 1961.

Ippen, A. T. and Harleman, D. R. F.: Two dimensional aspects of salinity intrusion in estuaries: analysis of salinity and velocity distributions., US Army Corps Eng., Comm. Tidal Hydraul., Tech. Bull. No. 13., 1967.

Kuijper, K. and van Rijn, L. C.: Analytical and numerical analysis of tides and salinities in estuaries; Part II: Salinity distributions in prismatic and convergent tidal channels, Ocean Dynam., 61, 1743-1765, 2011.

Langbein, W. B.: The hydraulic geometry of a shallow estuary, Int. Assoc. Scient. Hydrol. Bull., 8, 84-94, 1963.

Nguyen, A. D. and Savenije, H. H.: Salt intrusion in multi-channel estuaries: a case study in the Mekong Delta, Vietnam, Hydrol. Earth Syst. Sci., 10, 743-754, doi:10.5194/hess-10-743-2006, 2006.

Pethick, J.: An Introduction to Coastal Geomorphology, Edward Arnold Pub., London, 260 pp., 1984.

Rigter, B. P.: Minimum length of salt intrusion in estuaries, J. Hydr. Eng. Div.-ASCE, 99, 1475-1496, 1973.

Savenije, H. H. G.: A one-dimensional model for salinity intrusion in alluvial estuaries, J. Hydrol., 85, 87-109, 1986.

Savenije, H. H. G.: Salt intrusion model for high-water slack, lowwater slack, and mean tide on spread sheet, J. Hydrol., 107, 9-18, 1989.

Savenije, H. H. G.: Lagrangian solution of St. Venant's equations for alluvial estuary, J. Hydraul. Eng., 118, 1153-1163, 1992.

Savenije, H. H. G.: Composition and driving mechanisms of longitudinal tidal average salinity dispersion in estuaries, J. Hydrol., 144, 127-141, 1993a.

Savenije, H. H. G.: Predictive model for salt intrusion in estuaries, J. Hydrol., 148, 203-218, 1993b.

Savenije, H. H. G.: Salinity and Tides in Alluvial Estuaries, Elsevier, New York, 194 pp., 2005.

Savenije, H. H. G.: Salinity and Tides in Alluvial Estuaries, 2nd Edn., available at: http://salinityandtides.com/ (last access: 8 December 2014), 2012.

Schultz, E. A. and Simmons, H. B.: Fresh water-salt water density currents: a major cause of siltation in estuaries, in: Comm. Tidal Hydraul., Tech., Bull. No. 2, US Army Corps Eng., Vicksburg, MI, 1957.

Shaha, D. C. and Cho, Y.-K.: Comparison of empirical models with intensively observed data for prediction of salt intrusion in the 
Sumjin River estuary, Korea, Hydrol. Earth Syst. Sci., 13, 923933, doi:10.5194/hess-13-923-2009, 2009.

Thatcher, M. and Harleman, D.: A mathematical model for the prediction of unsteady salinity intrusion in estuaries, in: R. M. Parsons Laboratory Report, No. 144, MIT, Cambridge, Massachusetts, 1972.

van der Burgh, P.: Ontwikkeling van een methode voor het voorspellen van zoutverdelingen in estuaria, kanalen en zeeen, Rijkwaterstaat Rapport, Rijkswaterstaat, 's-Gravenhage, 10-72, 1972.
Van Os, A. and Abraham, G.: Currents and Salt Intrusion, Lecture Note for the Hydraulic Engineering Course at IHE-Delft, Delft Hydraulics, Delft, 1990.

Van Rees, A. J. and Rigter, B. P.: Flume study on salinity intrusion in estuaries, Proc. Congr. Int. Assoc. Hydraul. Res. 13th, 303310, 1969.

Zhang, E., Savenije, H. H. G., Wu, H., Kong, Y., and Zhu, J.: Analytical solution for salt intrusion in the Yangtze Estuary, China, Estuar. Coast. Shelf S., 91, 492-501, 2011. 